\title{
Teachers and Moral Development of Learners: A Case for a Kohlbergian and Neuroscience Approach
}

\author{
Petro van Niekerk \\ Department Educational Foundations, University of South Africa \\ vniekmp@unisa.ac.za
}

\section{Doi:10.5901/mjss.2014.v5n4p340}

\section{Abstract}

\begin{abstract}
This article focuses on the issue of development of morality in formal schooling and how best teachers can be equipped to become morally accountable professionals who can create a climate where learners are encouraged to exhibit ethical behaviour. Grounded in two complementary moral development theories, namely Kohlberg's theory and neuroscience, I indicate why it is essential for teachers to have a clear understanding of these theories in order to be informed how children acquire moral reasoning skills and how best to guide them. While Kohlberg's theory emphasises the importance of the development of critical rational abilities to address moral dilemmas in life, the contribution of neuroscience lies in that it emphasises the evolutionary development of the brain and mind. I argue that if known to teachers, these theories can serve as indices to understanding how learners acquire moral values.
\end{abstract}

Keywords: moral development, moral reasoning, teachers,: consciousness ethical behaviour

\section{Introduction}

In response to the question: "Can one teach basic moral principles such as respect for others, oneself and the environment in schools?" A response from educationists is likely to be: "yes, of course, this is what education and schooling is all about". However, when one examines the effectiveness of teaching values education formally in schools, one is astonished by social attitudes and practices that suggest a lack of moral fibre in many communities. This appears to be the case in South Africa. Media reports point to high levels of violence in schools and a general lack of respect for human life(Nkosi 2013:4-12; De Wet 2007) This suggests that it could be highly problematic to enact moral principles in practice, because these principles do not primarily function at an official and cognitive level. It is much more difficult to change people's hearts, habits and actions than to proclaim value statements in official policy documents and to teach values formally in subjects like Life Orientation. This begs the following questions: "Where does morality come from? Will a better understanding of morality in teacher education programmes inspire teachers to exemplify moral values in their classes? What role can teachers play to create an environment conducive to moral consciousness amongst learners? Will learners subsequently become morally accountable citizens? What contribution can moral development theories such as Kohlberg's theory and theories of human evolution like neuroscience make to inform teachers? How do views from neuroscience complement the views from Kohlberg's theory? What role can spirituality and wholeness in the consciousness of teachers play in the advancement of becoming morally accountable citizens who exhibit an ethics of care?

In this article I examine issues of moral development in formal schooling and argue that an investment in teachers' awareness of their own moral values so that they embody the moral principles and exhibit those in their professional conduct cross-curricular. My argument is framed within two complementary moral development theories, namely Kohlberg's theory (1984) and relevant developments in neuroscience theory (Arbib, 1999; Lackoff \& Johnson, 1999). First, I focus on how moral judgements are made. Next I point to the importance of an essential spiritual dimension of morality. Finally, I suggest some implications which a broader perspective of morality could have for teachers and teacher educators. I advocate the need to include more philosophical theorising into teacher education curricula in order to improve teachers' awareness of their role as moral leaders in their classrooms. I finally propose that making a greater investment in teacher education programmes by focusing on wholeness and spirituality rather than by adding more subjects to the school curricula (such as Life Orientation) will have greater long-term benefits for the moral status of teachers and learners (Prinsloo, 2007).

I concur with the view that teachers cannot avoid transmitting values, as education in general and schooling in 
particular are primarily value-laden and fundamentally moral endeavours. However, I believe that values cannot effectively be taught as a subject in the formal curriculum in the same way as factual information. Rather, they should form part of the consciousness of teachers who should deliberately make an effort to teach learners moral reasoning skills across the curriculum. More importantly, teachers ought to behave as morally accountable professionals and act as role models to youngsters in the classroom, because youngsters often internalise behaviour patterns which they observe from other persons rather than from subjects taught at a factual level (Pillay, 2012). Moreover, a literature review in a longitudinal study has found that teachers who were equipped with critical reasoning skills in their training and could reason at a post-conventional or principled level had a heightened awareness of their own values and took their ethical responsibilities, namely to emphasise the moral dimensions of their subject teaching in the classroom more seriously than those who reasoned at lower levels(Cummings, Harlow, \& Cleborne \& Maddux (2007). The same study found that teachers in general are not aware of their own value systems and often lack knowledge about moral development theories and the way they can influence the learners' abilities to engage in moral reasoning and thus to become responsible oral citizens.

\section{Clarification of Concepts}

Before embarking on an exposition of theories of moral development, I wish to distinguish between morals, ethics and values and thereafter give a brief summary of certain inherent basic assumptions of values in education and how they manifest in society. The Greek word ethos, meaning character or wisdom, refers to principles or standards of human conduct (i.e. the way one ought to behave). In Latin, principles or standards of conduct are called mores, meaning customs. Thus the study of principles or standards of human conduct is called moral philosophy. However, the concept of value is a more fundamental concept in philosophy, education, psychology and the social sciences in general. The Latin word valere from which the word 'value' stems, refers to that which is worth living and striving for. ((Nieuwenhuis 2007) For example, when one is confronted with a challenging reality to which one has to respond, values place an imperative on one to act in a manner consistent with that which one regards as worth striving or living for and actions one attaches meaning to. Those things and actions which individuals and communities attach meaning to, will be reflected in their everyday behaviour and actions (Frankl, 1984). Values underpin actions and not the other way around. It is seldom possible to enforce specific values, such as formulated in mission statements, and policies to change people's inherent beliefs and conduct On the contrary, in reality one would be able to observe people's actions and then derive from that their 'lived' values which are in fact the 'real' existing value system of a community or an individual. Moral principles, however, have to do with what a community regards as right and wrong. Almost all people agree that actions such as rape, murder and lack of respect for others constitute unacceptable behaviour. Having said that, the question remains, can teachers enact moral values in schools effectively in order to bring about behaviour changes in schools and society? What role can a better understanding of morality play to inspire teachers to portray moral values in their conduct crosscurricular?

In the ensuing section I discuss two distinct moral development theories and give examples how these theories have implications for teaching moral values in practice.

\section{Theories of Development}

The relevant sources in literature which were analysed focused on two main theories, namely Kohlberg's conventional theory of moral development and the more recent, somewhat unconventional theory of neuroscience.

\subsection{Kohlberg's theory on moral development}

Following in the footsteps of the French child psychologist Jean Piaget, Lawrence Kohlberg (1984) was one of the early thinkers to develop a theory of moral development based upon the stage theory of Piaget. He attempted to establish the existence of a series of stages through which people pass as they develop their abilities to reason about morality. His ideas were based on the assumption that there is a clear relationship between cognitive development and moral reasoning (Cummings et al., 2007). According to Kohlberg, moral development proceeds through three levels: the preconventional, conventional and post-conventional, with each level consisting of two stages. He illustrates his typology (Moral Judgement Interview MJI) with the responses which he gathered from his interviewees about a moral dilemma, such as the story of a man called Heinz whose wife was terminally ill and in need of a specific drug which he wanted to 
buy but could not afford. He consequently stole from the only druggist in the small town who had the drug so that she could survive.

At pre-conventional, stage one, the child assumes that powerful authorities handed down a fixed set of rules which must be obeyed unquestioningly, otherwise severe punishment will follow. This is in accordance with Piaget's preoperational phase where children do not speak as members of a society. Youngsters just responded to Heinz's story by saying that stealing is against the law. They regarded morality as external to themselves.

In stage two, still at the pre-conventional level, persons recognise that there is more than one right answer to a dilemma, but the solution is found on the basis of the fulfilment of their own desires only. The youngsters said Heinz did nothing wrong, because he had to fulfil his need to save his wife.

At the third stage, namely conventional morality, two levels feature: (1) to believe that good behaviour means having good motives and (2) to believe that interpersonal feelings such as trust and concern for others make any behaviour just and morally good. The youngsters responded by saying that Heinz's behaviour was morally good because of his good intentions.

During stage four, the person becomes gradually more concerned with society as a whole as well as with how important it is to maintain the social order. The youngsters understood Heinz's predicament, but said that society will fall into chaos, if this kind of theft is condoned. At this level moral decisions are being made, as society as a whole is being considered.

At the fifth stage, post-conventional morality steps in as people realise that a smoothly functioning society that condones during stage four is not necessarily a good social order. A totalitarian society might be well organised, but is hardly a moral ideal. People start to ask, what makes a society good? In response to Heinz's dilemma, many would argue that they are not generally in favour of breaking the law, as laws are social contracts that we agree to uphold until we can change them through democratic processes, but the wife's right to live is a moral right that needs to be protected.

In stage six, general responses follow philosophers like Kant and Rawls who believed in universal moral principles which are applicable to all; that is, principles of justice according to which all claims of all parties should be treated in an impartial way, respecting the basic dignity of all people as individuals. Kohlberg therefore says that just decisions can only be taken by looking at a situation through one another's eyes or so-called 'role taking'. In Heinz's dilemma, all the parties, the druggist, the wife and Heinz, take the roles of the others. If the druggist did this, he would realise that life must take priority over property, as he would not have liked to be in the same position as Heinz's wife. Thus they would all agree that the wife must be saved to make for a fair solution. The principle that everyone is given full and equal respect offers the only fair solution, as the principle of justice through impartiality has a universal character, according to Kohlberg.

Kohlberg, in contrast to Piaget, does not believe that these stages come about due to maturation, but rather as products of socialisation in an indirect, subtle manner. This means that parents and teachers cannot necessarily directly teach forms of moral thinking in a formal curriculum. These stages emerge from our own thinking about moral problems. Social experiences do promote development, but they do so by stimulating our mental processes. This is especially done by role-taking opportunities, opportunities to consider the viewpoints of others (Kohlberg, 1984). For example, as children interact with others, they learn how viewpoints differ and how to coordinate them in cooperative activities. As they discuss their problems and work out their differences, they develop their conceptions of what is fair and just.

In the next section, I would like to elaborate on certain key features of the neuroscience theory which relates to moral development and which I consider to be important in order to make sense of the implications these might have for teachers.

\subsection{Neuroscience theory}

In discussing the theory of neuroscience, various aspects come to the fore, such as the origins of the theory and the emergence of consciousness, which point directly to the danger of dualism and reductionism when dealing with human consciousness. I focus on the importance of feelings and intentionality when making moral judgements and then point to some important contributions of neuroscience to the understanding of moral development. I conclude the main discussion on moral development theories by alluding to the issue of wholeness and spirituality which I argue could enrich the views on morality and ethics in schools and society. 


\subsubsection{Origins of neuroscience}

In examining the origins of neuroscience theory it becomes clear that neuroscience is embedded in the broad field of the sciences of mind, comprising cognitive science and artificial intelligence (Du Toit, 2002). Although neuroscience forms part of cognitive science, different emphases exist. Cognitive science predominantly emphasises the mental functioning of the brain, processes of motor control, of perception, of recognition, retention and memory in human learning, while neuroscience tries to understand the neurobiological substrate of human behaviour (Arbib, 1999). Towards the mid1990s recent developments occurred within neuroscience itself, such as the neurobiology's focus on the biological/evolutionary basis of rationality, human emotions and experiences (Du Toit, 2002). For example, the capacity to find meaning, and hence value systems and religion, was not possible until the emergence of the neo-cortex which provided the capacity for consciousness, language and words.

The emergence of consciousness, some 300000 years ago, played a pivotal role in human capacity for moral development. It is interesting to note that consciousness, whether animal or human, implies a conscious body, an ensouled body. That means that we share the ability to experience emotions such as anger, fear and loss, as well as the need to play with all conscious animals. Obviously, the more complex the conscious brain and the more complex the social structure in which that brain is formed, the wider the spectrum of emotions that will and can be demonstrated. When the linguistic mind emerges, an entirely new set of possibilities emerges in the universe, among others, religion and science, art, culture, laughing and crying (Kriel, 2002).

Furthermore, Lackoff and Johnson (1999) make the important point that we can assume that what we have inherited through evolution with regard to perception, thought and action operates below the level of consciousness. In other words, all our knowledge and beliefs are framed in terms of a conceptual system that resides mostly in the cognitive unconscious. It thus shapes how we automatically and unconsciously comprehend what we experience. These authors cite examples of these kinds of below conscious awareness actions. For example: when one is engaging in conversation, such as accessing memories relevant to what is said; comprehending a stream of sound as being language; dividing it into distinct phonetic segments, grouping them into morphemes, assigning a structure to the sentence, picking out words and giving them meaning appropriate in context; planning what to say in response. This just illustrates the complex nature of our beings as a result of our evolutionary past. If something so simple can have such complex ramifications, one can only imagine the level of complexity moral judgements pose to us. The fact that humans sometimes act due to primal emotions such as of fear, anxiety or feelings of being threatened, originates from our evolutionary past and cannot be morally judged as these actions stem from our subconscious mind to which we do not have immediate access.

Furthermore, when making moral judgements, it is crucial not to fall into the trap of dualism or reductionism. We ought to take the whole person in his or her environment and different contexts into account to avoid reductionism (Du Toit, 2002:2). Personhood cannot be explained in isolation; nor can the phenomenon of mind and consciousness: "Our brains have evolved primarily as organs of social cooperation and understanding, involving the construction of symbolic representation and the development of mechanisms to reach social agreement. Individual aspects of neuro-dynamics and neurochemistry cannot be properly understood without taking the societal aspects into account" (Teske,2001). Moreover, extant literature suggests that neuro-science alone cannot provide a complete account of human nature or human spirituality because these are emergent properties that come about as a result of social and environmental interaction (Teske, 2001:96; Damasio 1994).

A final aspect of neuroscience theory is to recognise the importance of feelings and emotions when making any moral judgements. This characteristic of neuroscience theory is in stark contrast to Kohlberg's theory that focuses primarily on rationality. In contrast to Kohlberg, Damasio (1994) points out that emotion and feelings are essential to the processes of rational thought. This conclusion is based on clinical studies of patients with lesions to the pre-frontal lobes, each of whom exhibits a clear link between the loss of emotion and feeling and an inability to reason. Moreover, Damasio (1994) distinguishes between primary emotions and secondary emotions. Primary emotions, such as fear, flight, feeding and the need for mating, are located in the 'old' brain in the limbic system, the amygdale, and are held in the subconscious. These primary emotions are followed by mechanisms of secondary emotions located in the prefrontal cortices. These secondary emotions are displayed when we begin to experience feelings and form systematic connections between categories of objects or situations on the one hand and primary emotions on the other. Persons with damage in the prefrontal cortices cannot generate emotions relative to images of a situation or stimuli and therefore cannot have the ensuing feeling. Primary and secondary emotions work in unison and influence decision-making, as they make some options more desirable than others. Damasio (1994) points out that one can say that rational choices depend 
as much on the exercise of emotion and feelings as on logical deliberation. It is important to keep both in balance. It is precisely this aspect that makes the latest findings from neuroscience so fascinating. Both the prefrontal cortex (rational ability) and the emotional centres of our brain are vulnerable to our stress levels, unique circumstances and past hurt experiences as we want to make decisions. In training the brain to keep balance, by nutrition, physical activity, mental stimulation but not overload, spirituality and socialisation, better decisions can be made (Wallace \& Nussbaum, 2012).

\subsubsection{Contribution of neuroscience}

Although neuroscience might give the overall impression of being solely focused on brain processes emanating from our evolutionary past, this is not the final word. There is enough evidence from the latest developments (Freeman, 1999; Edelman, 1989; Walmsley, 2002) that other issues such as intentionality, feelings, values and meanings encountered by the individual in his or her social environment - even spirituality - are more influential when it comes to making moral choices.

This brings us to the important role of schooling as an influential arena of experience where meaning and value are assimilated into the neuronal connections of students (Sankey, 2006). We need other selves in order to become truly ourselves. What Sankey then advocates for is "to recognise that we are multi-levelled psychosomatic neuronal selves", whereby we can overcome the Cartesian dualism. This is precisely the contribution of neuroscience: it makes us realise that reason is never disembodied, but arises from the nature of our brains and bodily experiences.

Neuroscience confronts us with a radically different stance from Kohlberg and Kant's theories, where rational reflection is the main tool for dealing with moral dilemmas. Neuroscience, on the other hand, wants us to reflect on our evolutionary past and therefore acknowledges that persons are holistic beings with feelings, emotions, needs and genetic inheritances and environmental factors which all play a role in making moral judgements. Sankey (2006:165) agrees with this line of thought by contending that although our brains play a major role in shaping our experiences, this is not to say that we are nothing but the physical processes in a material brain. The brain is primarily embodied in the whole organism (the individual). This argument is premised on the view that each human being is a multileveled psycho-somatic unity, a biological organism.

Consequently, the contribution that neuroscience makes is that it emphasises that values in education are more pivotal than ever before. Values and meanings encountered in the processes of education "not only influence the conscious choices and actions of students, they also contribute to the making of each individual brain and influence what each self would do when actions and choices are initiated subconsciously"(Sankey 2006:173-174)

In the next section I build on the argument which the views on neuroscience introduced, by paying attention to the important dimension of spirituality and wholeness without which I believe our understanding of morality and ethics will be incomplete and ineffective. I rely mainly on the work done by Prozesky and Kruger.

\subsection{Wholeness and spirituality to enrich morality and ethics}

Prozesky (2006) points out that all cultures have common agreement on supreme core values, such as generosity of spirit and action and integrity, although moral wisdom may differ from culture to culture in how particular ethical problems such as abortion and euthanasia will be viewed. It is therefore possible for us to talk about ethics beyond cultural differences. Ethics, says Prozesky (2006), must always extend to the wellbeing of other people of society locally and globally and of the environment. As such, ethics is the pull against our selfish desire to perceive others as a means to our own gratification, not as ends in their own right. In that sense ethics can never be less than a deep concern for the fulfilment of whole person - body, emotions, mind, social relationships and spirit. This makes spirituality a vital component of ethics if it is to be transforming and holistically enriching. Spirituality can be defined "as that dimension of our existence which enables us to experience ourselves as part of a greater totality, able to give to the physical world a certain translucence and warmth suggestive of a deeper higher kind of reality in contact with which we feel ourselves to be most truly fulfilled" (Prozesky 2006:132). In this sense a close relationship between spirituality and ethics can promote the wellbeing of others. Spirituality can help ethics to move from justice to love and compassion, from a balancing of selfactualisation and the interests of others to an ability to accept even self-sacrifice.

I want to endorse the views of Prozesky pertaining to the close link between ethics and spiritual growth which happens when values, knowledge and concern for others converge with rich harmony and social action. For him soul is not a mysterious word, but "a coming together into unity all that is best in us - a caring heart, creative love that joins us to others in friendship and compassion, a free spirit and deep understanding of the Other born of a love of truth. Thus the 
soul in each of us, the living heart of our spirituality, enables us to become passionately ethical, ready to combat armies of greed and violence and to live and let live" (Prozesky, 2006). Kruger (2007) talks about wholeness as a unique capacity to experience mysticism, wonderment and transcendence.

In the next section, I indicate some implications for teachers and teacher trainers with regard to values education, keeping in mind both moral and theoretical frameworks.

\section{Implications for Teachers}

If principles, such as role-taking, can be learnt by social interaction, is there a role which teachers can play in order to teach values of justice and fairness? If so, how do they fulfil this role?

Cummings et al. (2007) make a strong case that teachers who reason at the post-conventional or principled level are more likely than teachers who reason at lower levels to motivate students' learning and healthy development and to have a heightened awareness of their own moral and ethical responsibilities. There is ample evidence in this study that these teachers have taken on their responsibility to emphasise the moral dimensions of teaching.

Hence if teacher education programmes could foreground the contribution of neurobiology and developmental psychology, teachers will have a better understanding of how they can influence children with regard to values in the school environment. For example, if a teenage boy of approximately 13 years old hits his classmate, he might have reacted out of rage, without having consciously decided to do that. Since the development of a 13-year-old brain is still ongoing, he might have acted from the region of the amygdale, the prime emotional centre of the brain which responds to basic feelings of fear and rage - emotions which might originate from a unstable home environment . In a climate of understanding and care, a teacher ideally should help such a child (the 'perpetrator') to verbalise his feelings instead of condemning him and scolding him. The teacher could assist him in reflecting on what had happened and in so doing portray the value of understanding, tolerance and patience with the human condition of imperfection, or past trauma, without condoning bad behaviour. She would also acknowledge by her actions that she knows that we do not always know why we do the things we do, as much of what constitutes our thinking and doing is below the level of consciousness, especially in the still developing brain/cognition/feelings. The ensuing discussion which she should have could highlight the value of respect for others which could not manifest in rage. In so doing she would also assist in enhancing the emotional wellbeing of the child by acknowledging and verbalising legitimate feelings and needs.

In the South African context, where violence in schools is rife, (Mncube in Nkosi 2013; de Wet 2007) teachers should be made more aware of how they could adopt a more humane approach towards dealing with learners misbehaviour. Teachers should have a better understanding of where deviant behaviour psychologically originates, e.g. conditions of emotional neglect, feelings of 'not being heard, frustrations and domestic violence at home. Consequently they will be better equipped to diffuse problematic situations in classrooms or playgrounds in a more humane way.

Thus, teachers must recognise that we often do not know why we do the things we do. The fact that we do not always have direct access to our minds, if much of what constitutes our thinking is below conscious awareness, limits the role that introspection can play in children. Nevertheless, teachers need to take up a broader sense of responsibility of looking at children and the school in a more holistic sense where learning to make ethical choices within our framework of socio-biological inheritance is crucial. This means that the teacher in the classroom should refrain from labelling a child who behaves in a disruptive manner as being immoral, but rather facilitate such a situation in a holistic manner, focusing on the intention, feelings and needs of a child, keeping in mind our evolutionary past as mammals who often act from our subconscious mind, primarily informed by fight or flight responses if feeling threatened or hurt. The work of Maslow (1943) on the hierarchy of needs is important in this regard as it represents a humanistic approach towards understanding human development to manifest in terms of underlying needs.

Furthermore, it is crucial for teachers, while they are inevitably busy with the transmission of values, to have a complete picture of the human self as a conscious/subconscious psychosomatic whole and to realise that "the school is an influential arena where meanings and values are assimilated into the neuronal connections that make students who they are" (Sankey, 2006:173). In general, this implies that if teachers can have knowledge of the social background from which learners come, they can have much more insight in how to approach a specific learner in an appropriate manner, with a view to making a constructive input in changing disruptive or immoral behaviour meaningfully with long-lasting effects. 


\section{Implications for Teacher Education}

In relation to Kohlberg's theory of moral development, it seems that teacher training programmes should sufficiently emphasise critical reasoning skills, to incorporate more abstract and theoretical content requiring student teachers to stretch themselves cognitively and thus equip teachers to facilitate moral reasoning in their classrooms. According to longitudinal studies done in the United Kingdom (Cummins et al 2007) the reason for the current lack of critical reasoning in the curricula for teacher education is the obvious demand for skills and methods devoted to subject knowledge and technical competence at the expense of cognitively more demanding courses It is clear, therefore, that different curriculum emphasis (for example more critical reflection) for teacher education is urgently needed Teacher education students should be exposed to content that is thought-provoking and challenges their thinking. Moreover, Yeazell and Johnson (1988) suggest that the study of moral reasoning and ethical dilemmas should form a central part of teacher training programmes. In a longitudinal study conducted by Reiman \& Peace 2002), it was conclusively found that the cohort of teacher students who had themes like social role-taking with guided reflection included in their study package, could to a greater extent reason at a post-conventional moral level. They were also more capable of debating moral dilemmas when these were discussed in peer groups.

Moreover, as findings from neuroscience studies reveal, a holistic and integrated view of a person is favoured. According to this view, a human being is a unique, multileveled psycho-somatic unity, a biological organism in constant dialogue with the outside environment. Moreover, it has become apparent that our social interactions can transform our inherited individuality into the consciousness of our being, tailoring our ability to make choices and have values. That implies that the school has an influential role to play as an environment that can become a values-based learning environment, where children should be understood to be conscious/subconscious selves on the road to becoming adults - socially, psychologically, neuro-biologically and spiritually.

If teacher educators emphasise these insights from both theories in teacher education programmes, they might influence teachers to apply these valuable insights in practice, I believe teachers will be enabled to become moral role models to youngsters in their schools and thus to make a difference to society in future

South African schools are in dire need for greater compassion and an ethics of care exemplified by adults involved in education(Christie 2008; Giddy, 2012:23).

\section{Conclusion}

In this article I indicated that in order for teachers to impart values that would enable learners to become moral agents, they must be aware of their own values as they cannot avoid passing them on. I discussed two main moral development theories, of complementary nature, such as the theories of Kohlberg and neuroscience. I explored a variety of options available for teachers to emphasise the moral content of their subject teaching in classrooms and indicated the implications of theories of moral development for teachers and teacher educators. I suggested that more theoretical subjects in teacher education programmes should be included since there is currently an overemphasis on technical skills. There should be adequate opportunities for student teachers to engage in discussions around moral dilemmas to equip teachers to consciously teach learners moral values as part of teaching their subjects. Adequate knowledge about moral development theories and the social contexts where learners are coming from can assist teachers to have a better understanding of moral development and how to guide children to become morally accountable human beings.

I argue that as far as the effective inculcation of moral principles such as honesty and respect for human life is concerned, one needs to be critically aware of the complexity of this task. In order for young persons to internalise values, they need to consistently see those values being embodied by their teachers and other adult role models. No attempts of teaching subjects like Life Orientation or Citizen Education, however good the intentions, should fool educators, as the value of content knowledge can simply remain at the official level and does not necessarily penetrate the level of 'lived' values or the formation of moral consciousness of learners. I rather advocate that teachers should model moral behaviour in being caring and professional teachers in their everyday practices. Moreover, I suggest that a mindset of wholeness and spirituality should be adopted in teacher education. Such a stance can complement teachers' awareness of their own value system and in so doing be passed on to the consciousness of learners in future. Ideally such a mindset should be portrayed by communities and society at large. I think even small beginnings can make a difference to a world overwhelmed by conflict and greed. In practice this can begin with one single teacher who lives the belief "Do to others what you want them to do to you." 


\section{References}

Arbib, M. (1999). Towards a neuroscience of the person, in Russel JR et al (ed) Neuroscience and the person, (pp77-100). Vatican City State: Vatican Observatory Publications.

Christie, P. (2008). Changing schools in South Africa: Opening the doors of learning. Sandton::Heinemann

Cummings, R., Harlow, S, Cleborne, R. Maddux (2007). Moral reasoning of in-service and pre-service teachers: a review of the research. Journal of Moral Education, 36 (1),67-78.

Damasio, A.(1994). Descartes' error: emotion, reason, and the human brain. New York: Putman Books.

De Wet, NC.( 2007). Violence in schools., (pp 248-261) In Wolhuter, CC; Lemmer, EM; de Wet, NC. (eds) Comparative Education:education systems and contemporary issues.Pretoria: Van Schaik.

Du Toit, C.W. (2002). The metaphysical mind in its physical environment: Religious implications of neuroscience, (pp1-27).in Du Toit, CW (ed) Brain, mind and soul: unifying the human self. Research Institute of Theology and Religion. University of South Africa.

Edelman, G.M. (1989). The remembered present: a biological theory of consciousness. New York: Basic Books.

Frankl, V.E. (1984). Man's search for meaning. New York: Washington Square Press.

Freeman, W. (1999). How brains make up their minds. London: Weidenfield \& Nicholson.

Giddy, P. (2012). Philosophy for children" Developing a framework. South African Journal of Education, 2012, (32),15-25.

Kohlberg, L. (1984). Essays on moral development: a psychology of moral development. The nature and validity of moral stages.Vol 2. San Francisco: Harper \&Row.

Kriel, J. (2002). And the flesh became mind: evolution, complexity and the unification of animal consciousness, (pp135-178) In Du Toit CW (ed) Brain, mind and soul: unifying the human self. Research Institute of Theology and Religion. University of South Africa.

Kruger, J.S. (2007). Turning points in Buddhist mysticism and philosophy. Pretoria: Aurora Press.

Lackoff, G.A. \& M. Johnson (1999). Philosophy in the flesh: the embodied mind and its challenge to Western thought. New York: Basic Books.

Maslow, A. (1943). Motivation and personality. San Francisco: Harper \& Row

Nieuwenhuis, J. (2007). (ed). Growing human rights and values in education. 1'st edition Pretoria:Van Schaik Publishers.

Nkosi, B (2013).Mail and Guardian, 4 April pp3-12

Pillay, J. (2012). Keystone Life Orientation (LO) teachers: implications for educational, social, and cultural contexts. South African Journal of Education. 30 (2), 167-177

Prinsloo, E. (2007).Implementation of Life Orientation Programmes in the new Curriculum in South African schools: perceptions of principals and Life Orientation Teachers. South African Journal of Education, 27(1)155-170

Prozesky, M. (2006). Ethics, spirituality and the secular In Du Toit, CW \& CP Mason (eds). Secular Spirituality as a contextual critique of Religion,(pp 127-138). Research Institute of Theology and Religion. University of South Africa.

Reiman, A. \& S.D. Peace (2002). Promoting teachers' moral reasoning and collaborative inquiry performance: a developmental roletaking and guided inquiry study, Journal of Moral Education 31(1),51-66.

Sankey, D. (2006). The neuronal synaptic self: having values and making choices. In Journal of Moral education, 35(2)163-178.

Teske, J.A. (2001). The genesis of mind and spirit. Zygon, 36(1),93-104.

Yeazell, M.L. \& S.F. Johnson (1988). Levels of moral judgement of faculty and students in a teacher education program: a micro study of an institution. Teacher Education Quarterly, 15 (1)pp 61-70

Wallace, R.K. \& P.D. Nussbaum 2012. "Your brain is plastic" Odyssey, 36(1),68-71.

Walmsley, G. 2002. Methodology, modalities of consciousness and the mind-body problem, (pp 225-274), In Du Toit, CW (ed) Brain, mind and soul: unifying the human self. Research Institute of Theology and Religion. University of South Africa. 